\title{
FACTORS INFLUENCING THE DECISION OF CONVENTIONAL/HYBRID LIGHTWEIGHT DESIGN STRATEGIES AND THEIR EFFECT ON THE DESIGN PROCESS
}

\author{
P. Schmitt ${ }^{\bowtie}$ and K. Gericke \\ University of Rostock, Germany \\ $\triangle$ pascal.schmitt@uni-rostock.de
}

\begin{abstract}
Lightweight design (LWD) is partly reaching its limits. New technologies must not only be used to make products more functional, but also to make LWD more efficient. Here additive manufacturing (AM) should be named. Potentials of the use in LWD are not yet clear. In this work, existing LWD strategies and their location in the design process are presented. Criteria are worked out which influence the design process and the use of LWD strategies. The use of AM in (hybrid) LWD will be investigated in order to overcome design trade-offs and what influence its use could have on the design process.
\end{abstract}

Keywords: lightweight design, hybrid lightweight design, additive manufacturing, design process

\section{Introduction}

Product requirements stemming from e.g. customers, competitors, suppliers or legislators are often contradictory. In the automotive industry, for example, customer needs that lead to additional functions often result in an increase in weight. This is in conflict with legislation which imposes restrictions with regard to emission targets. One way to solve this contradiction is to minimise weight by using one of the existing lightweight design strategies. Conventional lightweight design, however, is reaching its limits and new opportunities and technologies are constantly explored in order to meet this challenge. This includes additive manufacturing (Fischer et al., 2014).

Additive manufacturing (AM) is the "process of joining materials to make objects" (ASTM International, 2012) and belongs to the generative manufacturing methods. AM offers new degrees of freedom in design, minimal tooling time, minimal material wastage, reduced lead time, increased feature complexity without effects on cost, suitability for one-offs and small batches compared to other manufacturing techniques (Elder, 2012; Ponche et al., 2012; Seepersad, 2014; Yang et al., 2015; Lachmayer and Lippert, 2017). Due to the increasing variety of available materials AM is becoming increasingly important not only for prototypes but also for the production of parts.

AM has disadvantages and limitations like any other procedure. Currently, aspects of applicability in society, industry and education are being addressed (Ponche et al., 2012; Mellor et al., 2014; Seepersad, 2014). However, little attention has been paid to consequences for the designer, the design process, or the product architecture. While AM is seen as a promising approach for niches 
where conventional approaches reach their limits, for example in lightweight design (Fischer et al., 2014) its effective and appropriate use needs further research.

This paper aims to increase the understanding of the use of AM in the context of lightweight design in order to exploit its potential to the optimum. In this paper the general approaches to lightweight design are considered and how they can influence the properties and the design process of the product. A possible application of AM will be discussed in the later part of the work.The work presented in this paper is guided by the following questions:

1. In which part of the design process is the decision for a lightweight strategy being made?

2. Which factors influence the decision for or against lightweight strategies?

3. How can trade-offs get overcome (by AM)?

4. How does the use of additive manufacturing affect the design process?

The research is based on a literature review. By considering the use of lightweight design and AM throughout the entire design process, the search range is correspondingly large. An initial screening of the topics of lightweight design, additive manufacturing and the design process was used for a broad range of relevant sources. Established databases such as Scopus or Google Scholar were used to find publications. This was followed by skim reading to filter the most relevant publications. The remaining publications were considered for the results presented here. For the question, which criteria have an influence on the selection of a lightweight design approach, influencing criteria are worked out. These represent a link between the known design process and lightweight design approaches. The dependencies between the criteria (referenced in Appendix A) and the dependencies between the criteria and the lightweight design approaches (referenced in Appendix B) are considered. Possible trade-offs (question 3) are highlighted as the basis for the discussion on question 3.

\section{Lightweight design (strategies)}

Lightweight design aims to make parts, products or structures as light as possible, within constraints (Tempelman, 2013).

\subsection{Classification}

Different approaches that assist lightweight design exist. One way of categorizing them is to distinguish between design strategies, construction methods and construction principles. However, some construction methods are sometimes considered as implementation measures, thus demarcation between categories is sometimes blurred (Puri et al., 2001; Carruth et al., 2011) The following list provides an overview of typical approaches that aim to support lightweight design to clarify how these terms are used in this work (Puri et al., 2001; Klein, 2009; Henning and Moeller, 2011; Öchsner, 2018):

- Lightweight design strategies (see Figure 1): Material LWD, structural LWD, conditional LWD, conceptual LWD and composite LWD (Klein, 2009)

- Lightweight construction methods: specify the type of conversion. For example, differential construction, integral construction, integrated construction, composite construction (Ellenrieder et al., 2013)

- Lightweight construction principles: Not only deals with weight reduction, but also with dynamic safety, general terms such as shape, topology, dimensions and materials.

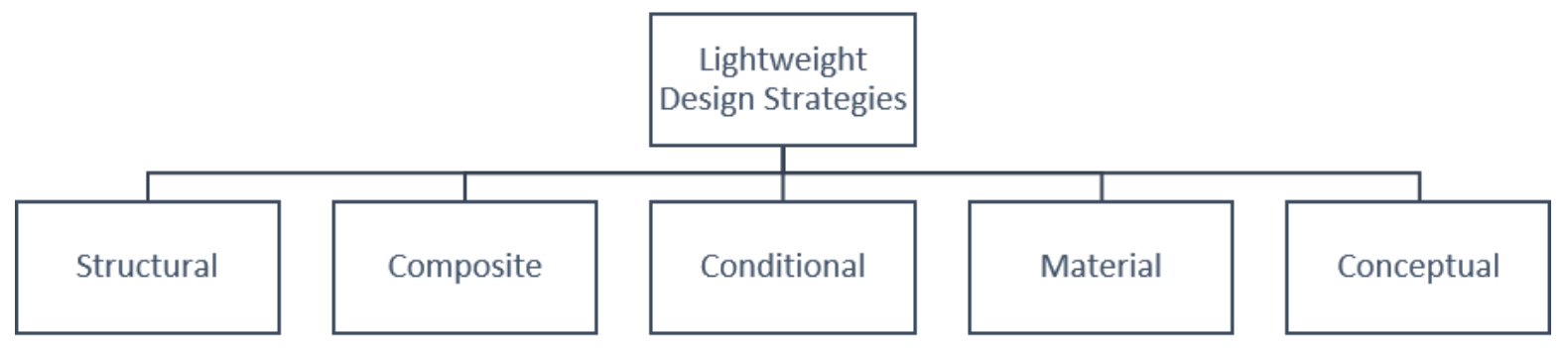

Figure 1. Lightweight design (LWD) strategies 
Structural LWD is the approach to minimize the required material while maximizing the exploitation of permissible stresses in a structure. Optimisation of geometries and load carrying structures requires information about cross-sections, loads and other boundary conditions.

Composite LWD combines different materials depending on the required product characteristics and the ability to utilise advantageous specific material properties. Besides fibre-reinforced materials which combine the low density and high tensile strength of e.g. carbon-fibres and the stiffness of a resin, also other combinations of different materials (e.g. FRP and aluminium) belong into this category. Besides mere weight reduction, this strategy also aims at integrating different functions into components by using different materials.

Conditional LWD aims at minimising safety factors, thus saving weight/avoiding overdesign, by a detailed analysis of the real occurring loads. If necessary, the entire structure or the environment is questioned in order to be able to integrate the component into an environment that permits lower strengths.

Material LWD focuses on weight reduction by substitution of a material using a material with better weight specific properties (e.g. aluminium instead of steel).

Conceptual LWD considers individual components and their optimal adaptation to the entire system. In this way, the entire system is optimized with regard to lightweight construction goals (Puri et al., 2001; Schumann, 2005; Zhang et al., 2007).

Economic aspects, addressing weight savings in relation to cost, also have an influence on the decision to use lightweight design. They are sometimes referred to as "lightweight design economy". They can be considered separately as they relate to all of the above-mentioned strategies (Ellenrieder et al., 2013).

\subsection{Integration into the design process}

LWD strategies have an influence on the product design on different levels; thus, they require different degrees of freedom for proper adoption. Subsequent changes to decisions, such as changing a conceptual strategy, lead to considerable additional costs. While a material substitution might be possibly quite late, other strategies have a bigger impact on the design and on design activities, thus have to be considered earlier in the process. Therefore, lightweight design strategies have to be implemented at an appropriate stage of the design process to utilise them to their full effect. Figure 2 shows the allocation of the different lightweight design strategies according to the different phases of the design process (Puri et al., 2001; Pahl et al., 2007).

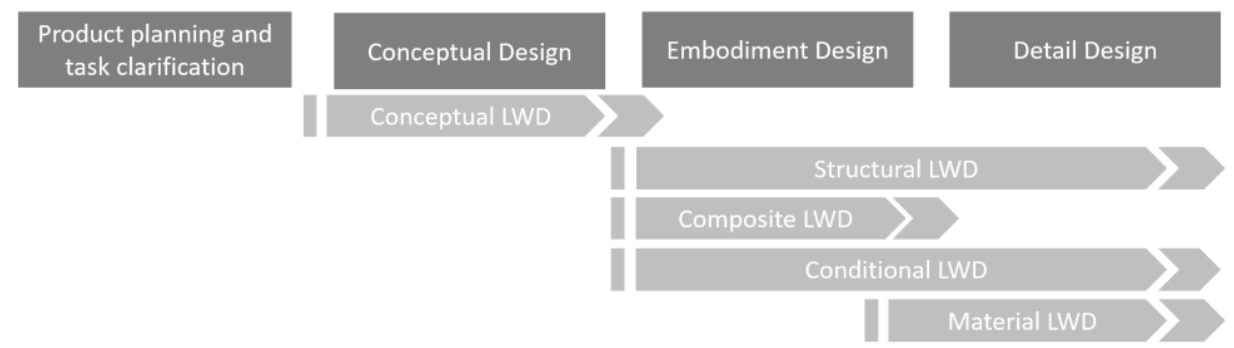

Figure 2. Allocation if lightweight design strategies in the design phases (Puri et al., 2001)

When using a conceptual lightweight design strategy, the product architecture is adapted to lightweight design goals, which might affect the architecture of the entire system or of sub-systems. Hence, this strategy needs to be implemented during the conceptual design stage.

With the exception of material lightweight design, the use of the remaining strategies starts in the embodiment design phase. In this phase, the form and shape of (previous) defined modules are determined.

The material lightweight design strategy can be implemented even during the detail design phase (Puri et al., 2001).

\section{Selection criteria}

Each lightweight design strategy has its own advantages but also weaknesses, which might recommend or restrict their application (Klein, 2009). This section presents criteria that need to be considered when 
selecting a suitable lightweight design strategy. These criteria are based on Design-for-X guidelines. Based on scientific paper that describe the general design process and lightweight design, an attempt is made to summarise these in a meaningful way.

The majority of these criteria are general design objectives, such as "(high) safety", "(low) cost", or "(low) manufacturing time". The desired direction (low/high) is obvious for most of these criteria. However, for some like a "functional integration", the desired direction depends on the specific application. Interdependencies amongst these criteria will be analysed in the next section. Table 1 summarises the criteria that were identified as having a high relevance for the selection of a suitable lightweight design strategy.

\section{Table 1. Selection criteria for LWD strategies}

low weight

low costs

short manufacturing

time

short development

time

high safety

long lifetime (fatigue)

low environmental impact

customisation/system complexity

functional integration

high adaptability (flexibility)

high assemblability

legal guidelines
Weight is an important factor due to the correlation between consumption and cost of resources, as well as energy in moving parts (Mallick, 2010)

With regards to the economy, the general goal is to keep the costs low (Tu and Xie, 2003).

Cycle time that is needed to produce parts/products

Period required for designing a new product. This criterion and the one before can be combined to the time-to-market (Cohen et al., 1996; Schilling and Hill, 1998)

The non-existent danger for humans and the environment (Pahl et al., 2007).

Period of functional reliability of a technical system to assure the provided functionality (Pahl et al., 2007).

Effect of processes, materials and measures on the environment. Effects on the environment are unavoidable and can only be minimised/reduced, for example by environmental requirements (van Nes and Cramer, 2006).

The wish for customisation reflects the desire of customers for individual offerings. This goes along with a higher system complexity (Blecker and Abdelkafi, 2006; Raja, 2019). Complexity is caused by many internal and external factors. The internal complexity of products is determined by the product variety and the degree of so-called function integration (Raja, 2019). Optimizing product architecture can help to handle complexity (Ulrich and Eppinger, 1995).

Decreasing the number of parts by addition of functions into existing/fewer components is called "functional integration" (Wagner, n.d.; Hoenow and Meißner, 2016) and with regards to the named challenges a high functional integration is aspired.

Allowing the easy adaptation of product features to changing needs and requirements (customisation).

Reduction of time, cost, and failure (waste) during the manufacturing process. A high assemblability supports the successful introduction of a product (Polacsek et al., 2019)

Laws provide the legal framework for design. These may include recycling laws, consumer protection laws or patents.

The realisation of designs that satisfy these criteria depends on a variety of factors such as available resources (financial, personal, tools), capabilities and available materials and technologies.

The development of new materials, new manufacturing techniques such as Additive Manufacturing or new IT-supported design tools continuously change the boundaries of what is possible.

\section{Dependencies}

In the following section, the dependencies amongst the criteria and dependencies between the LWD strategies and selection criteria, as derived from the literature are summarised and analysed. While this overview does not claim to be exhaustive it allows to highlight trade-offs and to discuss effects of new enabling technologies (e.g. Additive Manufacturing) and changes in desired product characteristics (e.g. better sustainability). 


\subsection{Dependencies amongst the selection criteria}

None of the lightweight design strategies will satisfy all of the selection criteria at once, as the criteria are not independent, and many contradict each other. Analysing dependencies and trade-offs between criteria helps to understand implications of individual strategies before taking a decision on a particular strategy. The dependencies amongst the selection criteria that are shown in Table 2 are derived from the reviewed literature. An overview of the considered literature is given in Appendix A. Dependencies can be negative, positive or undetermined. An improved assemblability for example, likely leads to a decreased production time and lower costs. That means this is a positive combination. For certain combinations of criteria, dependencies are clearly positive or negative, e.g. the reduction of weight by any lightweight design strategy always requires a longer manufacturing time (Ehrenberger et al., 2013). In general, the development and manufacturing time, by trying to favour other criteria, rather increases. These include efforts to increase safety or minimize environmental damage (Kaebernick et al., 2003; Hale et al., 2007).

For other combinations unambiguous statements are not possible, as their relationships depend on additional influences, which can/should not be generalised.

The analysis reveals negative dependencies between some criteria, e.g. between "customization" and "short manufacturing time", "short development time" or "high functional integration". However, "customization" has positive dependencies with "high assemblability" and "high adaptability", which show positive dependencies with almost all other criteria. This suggests a potential for the use of AM as it is supposed to enhance assemblability and functional integration.

\subsection{Dependencies between the selection criteria and lightweight design strategies}

Table 2 shows the dependencies between the LWD strategies and selection criteria, i.e. the tendency of effects of LWD strategies on a product with regard to the selection criteria. As argued before, none of the LWD strategies will satisfy all criteria evenly. Thus, a suitable LWD strategy needs to be selected depending on the particular weighting of each criterion in a specific design project. The findings are based on the information about the criteria (shown in Figure 3), as well as further literature regarding the strategies (see Appendix B).

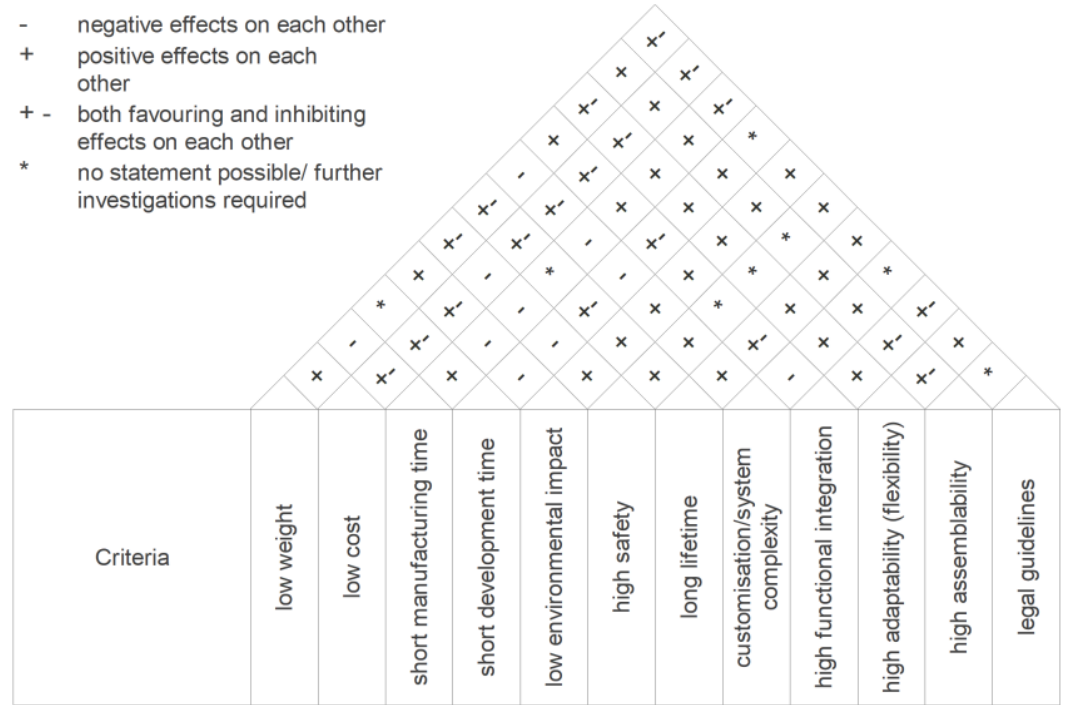

Figure 3. Dependencies between selection criteria

It is obvious that the criterion "low weight" can be realised with all strategies because it is the main goal of every single strategy. The effects on costs are much more complex. From a companies' point of view, lightweight design strategies are usually associated with an increase in costs. Weight savings realised by substitution of material or a refined structure usually result in higher additional costs compared to a weight reduction realised by conditional LWD (Klein, 2009). With regard to lightweight 
economy, the negative aspects, which include additional costs, must be surpassed by good arguments, i.e. by improving other criteria (Klein, 2009).

Material LWD and conditional LWD do not necessarily affect the architecture of a system, thus do not affect related criteria (e.g. customisation, adaptability, functional integration).

As shown in Table 2, composite LWD tends to have a negative effect on several criteria. Reasons for this are, amongst others, the challenges of interfaces between compounded materials made by different materials (Hackl and Bruckner, 2013). However, composite materials such as fibrereinforced polymers found their application in numerous fields, such as wind turbines rotor blades or car bodies. Thus, composite LWD obviously has other major advantages such as the possible weight reduction.

Table 2. Dependencies between the selection criteria and LWD strategies

\begin{tabular}{|c|c|c|c|c|c|c|c|c|c|c|c|c|}
\hline 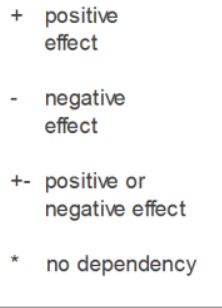 & 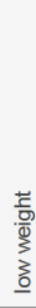 & $\begin{array}{l}\text { "0 } \\
\text { O } \\
\text { zo } \\
\text { of }\end{array}$ & 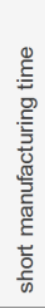 & 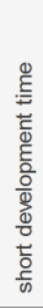 & 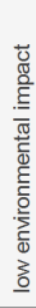 & 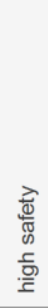 & 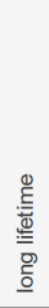 & 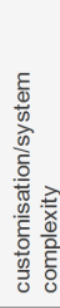 & 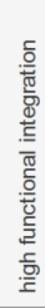 & 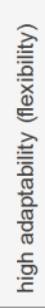 & 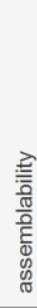 & 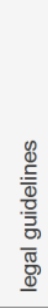 \\
\hline Conceptual LWD & + & +- & + & +- & + & +- & +- & + & + & + & + & + \\
\hline Strucural LWD & + & +- & +- & +- & + & +- & +- & + & + & + & + & + \\
\hline Composite LWD & + & - & - & - & +- & +- & +- & +- & +- & +- & + & +- \\
\hline Conditional LWD & + & +- & * & +- & + & +- & +- & * & * & * & * & + \\
\hline Material LWD & + & - & * & * & + & +- & +- & * & * & * & * & + \\
\hline
\end{tabular}

\section{Discussion}

Trade-offs in product development are unavoidable as explained in the previous section (see Figure 3, Table 2). As pointed out, while offering numerous advantages to customers, customised products have various disadvantages. These include challenges in realising functional integration. A composite LWD strategy is usually negatively connected to criteria that describe the system architecture such as "high adaptability", "high functional integration" and "customisation". Any positive effect will require additional costs. The following section deals with an approach to overcome these trade-offs.

Several studies have dealt with the use of additive manufacturing (AM) in lightweight design and have shown its potentials (Türk et al., 2018, 2019; Kussmaul et al., 2019). From the load-dependent adaptation of a honeycomb core to new possibilities to implement internal reinforcing components, the areas of application have been investigated.

Apart from the pure structural optimization, which can be assigned to structural LWD, one focus is the combination of additive components with other lightweight structures. This material combination in the field of lightweight design can be assigned to the term hybrid lightweight design.

Hybrid lightweight design is a relatively new field of research. Hybrid in the origin means, a mixed, crossed, bundled (Hummelberger, 2018). Hybrid lightweight design uses the construction method of multi-material design, which consists of at least two different materials. This can be subdivided into intrinsic and extrinsic (Hummelberger, 2018). The chronological order of the consolidation of both materials differs in the classification. In intrinsic production, the different materials are joined together during the production of the components. Extrinsic production means the two materials are joined after the individual components have been manufactured. Furthermore, hybrid material structures can be differentiated at panel level, structure level and component level (Ashby, 2016). 
Because of the subsequent joining of the structures, the approach can be classified as extrinsic manufacturing at component level. According to the classification of lightweight design strategies mentioned in section 2.1, hybrid lightweight design can primarily be assigned to the strategy of composite LWD. Due to the high degree of flexibility of additively manufactured components, both the complexity and the product architecture of products can be fundamentally changed. That could lead to an expansion of the applicability of associated strategies in the course of the design process as shown in Figure 4. Through an earlier application of composite LWD, new methods of conceptual lightweight construction can become possible. The use of various strategies after the concept phase is complete can be critically questioned. Especially since the concept phase holds great potential for lightweight design, it is desirable not to leave out the potential thereby making unsystematic decisions, as is often the case (Posner et al., 2014).

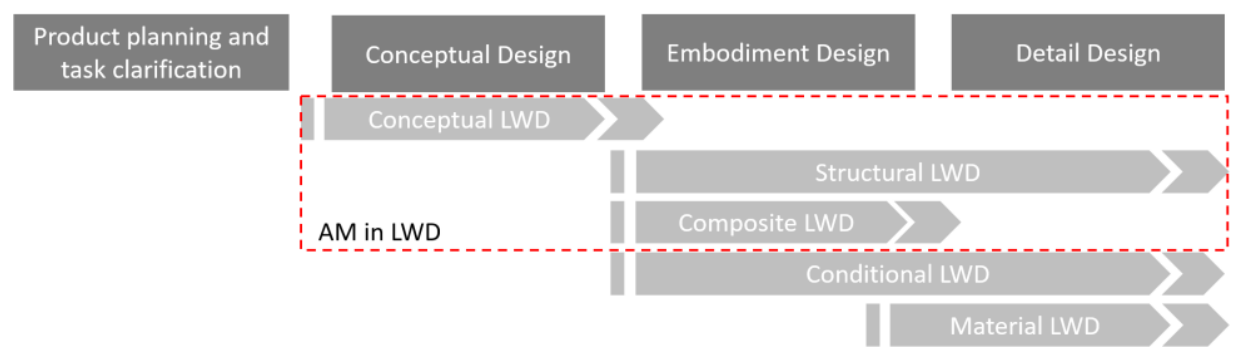

Figure 4. Allocation of additive manufacturing in lightweight design (AM in LWD)

Research into approaches that support the designer in using additive manufacturing by informing about advantages and disadvantages already exists. However, the role of AM in hybrid lightweight design and its influence on the development process has received little attention so far. It is expected that further research on hybrid lightweight design enabled by AM will help to better assess its effect on other LWD strategies (e.g. conceptual LWD), to understand its effect on the design process and ultimately to provide better support to designers.

\section{Conclusion}

Lightweight design is a highly constrained activity. Criteria for the selection of appropriate LWD strategies are often conflicting, thus a decision for a particular LWD strategy requires compromises which affect the design of a product, its economic success and its ecological impact. New technologies such as additive manufacturing hold the potential to relax the constraints that affect LWD. However, to utilise the full potential of AM in hybrid lightweight design, further research is required.

As presented in this paper, the use of AM has an influence on the design process and the product as a whole. The potential effects of additive manufacturing on lightweight design strategies are not fully understood yet. Previous examples are only selective. A derivation of generally valid statemens would be helpful. This raises the question of whether influences on the mentioned stress field can be derived from this. For factors such as the criteria mentioned, quantities or the phases of development, a suitable tool must be worked out. The aim is to ensure that designers are able to consider the appropriate use of AM in lightweight design from the early design phase onwards, even without experience, in order to make the best possible use of its lightweigh potential.

\section{References}

Ashby, M.F. (2016), Materials Selection in Mechanical Design, Vol. 5, ISBN: 9780081005996.

ASTM International (2012), "ASTM International, 'ASTM F2792 - 12a Standard Terminology for Additive Manufacturing Technologies,"”. https://doi.org/10.1520/F2792-12A

Blecker, T. and Abdelkafi, N. (2006), "Complexity and variety in mass customization systems: Analysis and recommendations”, Management Decision, Vol. 44 No. 7, pp. 908-929. https://doi.org/10.1108/0025174061 0680596

Carruth, M.A., Allwood, J.M. and Moynihan, M.C. (2011), "The technical potential for reducing metal requirements through lightweight product design", Resources, Conservation and Recycling, Vol. 57, pp. 4860. https://doi.org/10.1016/j.resconrec.2011.09.018 
Cohen, M.A., Eliashberg, J. and Ho, T.-H. (1996), "New Product Development: The Performance and Time-toMarket Tradeoff", Source: Management Science. https://doi.org/10.1287/mnsc.42.2.173

Ehrenberger, S. et al. (2013), "Recycling, Life-Cycle-Assessment und Rohstoffverfügbarkeit", in Leichtbau in der Fahrzeugtechnik. Springer Fachmedien, Wiesbaden, pp. 727-766. https://doi.org/10.1007/978-3-8348-2110-2_8

Elder, A. (2012), Additive Manufacturing, 3D Printing, and the Coming Stock Market Boom, 3rd Edition Elder.com e-book Series.

Ellenrieder, G. et al. (2013), "Die Leichtbaustrategien", in Leichtbau in der Fahrzeugtechnik. Springer Fachmedien Wiesbaden, pp. 43-118. https://doi.org/10.1007/978-3-8348-2110-2_3

Fischer, F., Kleemann, S. and Vietor, T. (2014), "Smart Production of Hybrid Material Automotive Structures at ForschungsCampus Wolfsburg in the 'Open Hybrid LabFactory", ITHEC 2014 - International Conference and Exhibition on Thermoplastic Composites.

Hackl, H. and Bruckner, J. (2013), “Auswirkungen des Multimaterial-Leichtbaus auf die Fügetechnik”, ATZ Automobiltechnische Zeitschrift. Springer Science and Business Media LLC, Vol. 115 No. 10, pp. 808-813. https://doi.org/10.1007/s35148-013-0279-9

Hale, A., Kirwan, B. and Kjellén, U. (2007), "Safe by design: where are we now?", Safety Science, Vol. 45 No. 1-2, pp. 305-327. https://doi.org/10.1016/j.ssci.2006.08.007

Henning, F. and Moeller, E. (2011), Handbuch Leichtbau - Methoden, Werkstoffe, Fertigung, Handbuch Leichtbau. Hanser.

Hoenow, G. and Meißner, T. (2016), Entwerfen und Gestalten im Maschinenbau: Bauteile - Baugruppen Maschinen. 4, Fachbuchverlag Leipzig im Carl Hanser Verlag, München.

Hummelberger, D. (2018), "Hybride Werkstoffsysteme: Systematische Betrachtung und Bewertung der physikalischen Wirkmechanismen".

Kaebernick, H., Kara, S. and Sun, M. (2003), "Sustainable product development and manufacturing by considering environmental requirements", in Robotics and Computer-Integrated Manufacturing, pp. 461-468. https://doi.org/10.1016/S0736-5845(03)00056-5

Klein, B. (2009), “Leichtbau-Konstruktion”, Leichtbau-Konstruktion. Vieweg+Teubner. https://doi.org/10.1007/ 978-3-8348-9965-1

Kussmaul, R. et al. (2019), "Individualized lightweight structures for biomedical applications using additive manufacturing and carbon fiber patched composites", Design Science, Vol. 5, p. e20. https://doi.org/ 10.1017/dsj.2019.19

Lachmayer, R. and Lippert, R.S. (2017), “Additive Manufacturing Quantifiziert”, Additive Manufacturing Quantifiziert. Springer, Berlin Heidelberg. https://doi.org/10.1007/978-3-662-54113-5

Mallick, P.K. (2010), Materials, Design and Manufacturing for Lightweight Vehicles.

Mellor, S., Hao, L. and Zhang, D. (2014), "Additive manufacturing: A framework for implementation", in International Journal of Production Economics, pp. 194-201. https://doi.org/10.1016/j.ijpe.2013.07.008

van Nes, N. and Cramer, J. (2006), "Product lifetime optimization: a challenging strategy towards more sustainable consumption patterns", Journal of Cleaner Production, Vol. 14 No. 15-16, pp. 1307-1318. https://doi.org/10.1016/j.jclepro.2005.04.006

Öchsner, A. (2018), "Leichtbaukonzepte”, Wiesbaden: Springer Fachmedien Wiesbaden (essentials). https://doi.org/10.1007/978-3-658-20604-8

Pahl, G. et al. (2007), "Engineering design: A systematic approach", Engineering Design: A Systematic Approach. https://doi.org/10.1007/978-1-84628-319-2

Polacsek, T. et al. (2019), "Design for efficient production, a model-based approach", in Proceedings International Conference on Research Challenges in Information Science. IEEE Computer Society. https://doi.org/10.1109/RCIS.2019.8877088

Ponche, R. et al. (2012), “A new global approach to design for additive manufacturing: A method to obtain a design that meets specifications while optimizing a given additive manufacturing process is presented in this paper", Virtual and Physical Prototyping, Vol. 7 No. 2, pp. 93-105. https://doi.org/10.1080/17452759.2012.679499

Posner, B., Hinz, H. and Roth, D. (2014), "Supporting Lightweight Design Potential Assessment in the Conceptual Phase", in Proceedings of International Design Conference, Design, pp. 353-362. issn: 18479073.

Puri, W., Meerkamm, H. and Schmidt, W. (2001), "Strategies and rules for lightweight design", Design Methods for Performance and Sustainability.

Raja, V. (2019), "On the Design of Functionally Integrated Aero-engine Structures Modeling and Evaluation Methods for Architecture and Complexity".

Schilling, M.A. and Hill, C.W.L. (1998), "Managing the new product development process: Strategic imperatives", IEEE Engineering Management Review. IEEE, Vol. 26 No. 4, pp. 55-68. https://doi.org/ 10.5465/ame.1998.1109051

Schumann, S. (2005), "The Paths and Strategies for Increased Magnesium Applications in Vehicles". https://doi.org/10.4028/www.scientific.net/MSF.488-489.1 
Seepersad, C.C. (2014), "Challenges and Opportunities in Design for Additive Manufacturing", $3 D$ Printing and Additive Manufacturing, Vol. 1 No. 1, pp. 10-13. https://doi.org/10.1089/3dp.2013.0006

Tempelman, E. (2013), "Lightweight Materials, Lightweight Design?", Materials Experience: Fundamentals of Materials and Design. Elsevier. https://doi.org/10.1016/B978-0-08-099359-1.00018-7

Tu, Y.L. and Xie, S.Q. (2003), Product development cost estimation and optimisation in a global manufacturing environment.

Türk, D.-A. et al. (2019), "Design and manufacture of hybrid metal composite structures using functional tooling made by additive manufacturing", Design Science. Cambridge University Press (CUP), p. 5. https://doi.org/ $10.1017 / \mathrm{dsj} .2019 .16$

Türk, D.A. et al. (2018), "Design and manufacturing of high-performance prostheses with additive manufacturing and fiber-reinforced polymers", Production Engineering. Springer Verlag, Vol. 12 No. 2, pp. 203-213. https://doi.org/10.1007/s11740-018-0799-y

Ulrich, K.T. and Eppinger, S.D. (1995), Product Design and Development, Fifth Edition: About the Authors.

Wagner, C. (n.d.), Funktionsintegration im Rahmen einer fertigungsgetriebenen Produktentwicklung. Available at: https://tuprints.ulb.tu-darmstadt.de/id/eprint/7528 (Accessed: 9 November 2019).

Yang, S., Tang, Y. and Zhao, Y.F. (2015), "A new part consolidation method to embrace the design freedom of additive manufacturing", Journal of Manufacturing Processes, Elsevier Ltd, Vol. 20, pp. 444-449. https://doi.org/10.1016/j.jmapro.2015.06.024

Zhang, Y. et al. (2007), "Technical Briefs Study on Structural Lightweight Design of Automotive Front Side Rail Based on Response Surface Method". https://doi.org/10.1115/1.2712223

\section{Appendix A}

Ashby, M.F. (2016), Materials Selection in Mechanical Design. p. 5.

Borchardt, M. et al. (2011), "Redesign of a component based on ecodesign practices: Environmental impact and cost reduction achievements", Journal of Cleaner Production, Vol. 19 No. 1, pp. 49-57. https://doi.org/10. 1016/j.jclepro.2010.08.006

Büter, A. (no date), "Nationale Bildungskonferenz Elektromobilität 2011 in ULM Forum 6: Funktions integrierter Leichtbau", Available at: https://www.fbmk.h-da.de (Accessed: 12 November 2019).

Carruth, M.A., Allwood, J.M. and Moynihan, M.C. (2011), "The technical potential for reducing metal requirements through lightweight product design", Resources, Conservation and Recycling, Vol. 57, pp. 48-60. https://doi.org/10.1016/j.resconrec.2011.09.018

Dewan, R., Jing, B. and Seidmann, A. (2000), “Adoption of Internet-based product customization and pricing strategies”, Journal of Management Information Systems. M.E. Sharpe Inc., Vol. 17 No. 2, pp. 9-28. https://doi.org/10.1080/07421222.2000.11045644

Ehrenberger, S. et al. (2013), "Recycling, Life-Cycle-Assessment und Rohstoffverfügbarkeit", In Leichtbau in der Fahrzeugtechnik. Springer Fachmedien, Wiesbaden, pp. 727-766. https://doi.org/10.1007/978-3-8348-2110-28

Elmarakbi, A. and Azoti, W. L. (2015), "Novel composite materials for automotive applications: concepts and challenges for energy-efficient and safe vehicles".

Emmelmann, C. and Klahn, C. (2012), Funktionsintegration im Werkzeugbau durch laseradditive Fertigung. Available at: https://www.dipp.nrw.de/service/dppl/ (Accessed: 8 November 2019).

Fiebig, S. et al. (2015), 07 th-12 th.

Hale, A., Kirwan, B. and Kjellén, U. (2007), "Safe by design: where are we now?", Safety Science, Vol. 45 No. 1-2, pp. 305-327. https://doi.org/10.1016/j.ssci.2006.08.007

Halstenberg, F. A. et al. (2015), "ScienceDirect Target-oriented Modularization-Addressing Sustainability Design Goals in Product Modularization”, Procedia CIRP, Vol. 29, pp. 603-608. https://doi.org/10.1016/ j.procir.2015.02.166

Howells, G. and Weatherill, S. (2017), "Consumer protection law".

Kaebernick, H., Kara, S. and Sun, M. (2003), "Sustainable product development and manufacturing by considering environmental requirements", in Robotics and Computer-Integrated Manufacturing, pp. 461-468. https://doi.org/10.1016/S0736-5845(03)00056-5

Klein, B. (2009), "Leichtbau-Konstruktion", Leichtbau-Konstruktion. Vieweg+Teubner, https://doi.org/10.1007/ 978-3-8348-9965-1

Klöpffer, W. (2003), "Life-cycle based methods for sustainable product development”, International Journal of Life Cycle Assessment. Springer Verlag, pp. 157-159. https://doi.org/10.1007/BF02978462

Koren, Y. et al. (2013), "Open-architecture products", CIRP Annals - Manufacturing Technology, Vol. 62 No. 2, pp. 719-729. https://doi.org/10.1016/j.cirp.2013.06.001

Körner, M., Höcker, F. and Böttcher, A. (2019), "Hybrider Achsträger erhöht Funktionalität und spart Gewicht", Lightweight Design. Springer Nature, Vol. 12 No. 1, pp. 52-55. https://doi.org/10.1007/s35725-018-0070-7 
Kušar, J. et al. (2004), "How to reduce new product development time", Robotics and Computer-Integrated Manufacturing, Vol. 20 No. 1, pp. 1-15. https://doi.org/10.1016/S0736-5845(03)00049-8

Lee, K.S. et al. (2008), "A study on the energy absorption characteristics of CFRP side member for fuelefficiency improvement and crush safety", In Materials Science Forum. Trans Tech Publications Ltd, pp. 81-84. https://doi.org/10.4028/www.scientific.net/msf.580-582.81

Lee, Y.-L. et al. (2005), Fatigue Testing and Analysis: Theory and Practice, Butterworth-Heinemann, Michigan, USA.

Luttropp, C. and Lagerstedt, J. (2006), "EcoDesign and The Ten Golden Rules: generic advice for merging environmental aspects into product development", Journal of Cleaner Production, Vol. 14 No. 15-16, pp. 1396-1408. https://doi.org/10.1016/j.jclepro.2005.11.022

Micklitz, H., Reich, N. and Rott, P. (2009), "Understanding EU consumer law". Available at: https://cadmus.eui.eu/handle/1814/31457 (Accessed: 8 November 2019).

van Nes, N. and Cramer, J. (2006), "Product lifetime optimization: a challenging strategy towards more sustainable consumption patterns", Journal of Cleaner Production, Vol. 14 No. 15-16, pp. 1307-1318. https://doi.org/10.1016/j.jclepro.2005.04.006

Pahl, G. et al. (2007), "Engineering design: A systematic approach", Engineering Design: A Systematic Approach. https://doi.org/10.1007/978-1-84628-319-2

Pourabdollahian, G. et al. (2014), "A Contribution toward a Research Agenda: Identifying Impact Factors of Mass Customization on Environmental Sustainability”, International Journal of Industrial Engineering and Management (IJIEM), Vol. 5 No. 4, pp. 169-178.

Raja, V. (2019), On the Design of Functionally Integrated Aero-engine Structures Modeling and Evaluation Methods for Architecture and Complexity.

Redelbach, M., Klötzke, M. and Friedrich, H.E. (no date), Impact of lightweight design on energy consumption and cost effectiveness of alternative powertrain concepts.

Roemer, T.A., Ahmadi, R. and Wang, R.H. (2000), "Time-cost trade-offs in overlapped product development", Operations Research. INFORMS, Vol. 48 No. 6, pp. 858-865. https://doi.org/10.1287/opre.48.6.858.12396

Sakundarini, N. et al. (2013), "Optimal multi-material selection for lightweight design of automotive body assembly incorporating recyclability", Materials and Design. Elsevier Ltd, Vol. 50, pp. 846-857. https://doi.org/10.1016/j.matdes.2013.03.085

Stephens, R.I. et al. (2000), Metal Fatigue in Engineering. John Wiley \& Sons, 2000.

Wagner, C. (no date), Funktionsintegration im Rahmen einer fertigungsgetriebenen Produktentwicklung. Available at: https://tuprints.ulb.tu-darmstadt.de/id/eprint/7528 (Accessed: 9 November 2019).

Whitney, D. (2004), Physical limits to modularity, Engineering Systems Symposium 2004.

Wiedemann, J. (2007), Leichtbau : Elemente und Konstruktion, Springer.

\section{Appendix B}

Carruth, M.A., Allwood, J.M. and Moynihan, M.C. (2011), "The technical potential for reducing metal requirements through lightweight product design", Resources, Conservation and Recycling, Vol. 57, pp. 48-60. https://doi.org/10.1016/j.resconrec.2011.09.018

Fiebig, S. et al. (2015), 07 th-12 th.

Gumpinger, T., Jonas, J. and Krause, D. (2009), "New approach for lightweight design: from differential design to integration of function", Internation conference on engineering design, ICED'09, pp. 6-201-6-210. https://doi.org/10.1017/CBO9781107415324.004

Kaluza, A. et al. (2016), "Analyzing decision-making in automotive design towards life cycle engineering for hybrid lightweight components", in Procedia CIRP. Elsevier B.V., pp. 825-830. https://doi.org/10.1016/ j.procir.2016.05.029

Klein, B. (2009), “Leichtbau-Konstruktion”, Leichtbau-Konstruktion. Vieweg+Teubner. https://doi.org/10.1007/ 978-3-8348-9965-1

Sakundarini, N. et al. (2013), "Optimal multi-material selection for lightweight design of automotive body assembly incorporating recyclability”, Materials and Design. Elsevier Ltd, Vol. 50, pp. 846-857. https://doi.org/10.1016/j.matdes.2013.03.085

Selvaraj, P., Radhakrishnan, P. and Adithan, M. (2009), "An integrated approach to design for manufacturing and assembly based on reduction of product development time and cost", J Adv Manuf Technol, Vol. 42, pp. 13-29. https://doi.org/10.1007/s00170-008-1580-8

Zhang, Y. et al. (2007), “Technical Briefs Study on Structural Lightweight Design of Automotive Front Side Rail Based on Response Surface Method”. https://doi.org/10.1115/1.2712223 